Brit. J. industr. Med., 1950, 7, 73.

\title{
DUST CONDITIONS AT SELECTED BRIQUETTING WORKS IN SOUTH WALES
}

\author{
BY \\ H. H. WATSON \\ From the Pneumoconiosis Research Unit (Medical Research Council), Cardiff
}

(RECEIVED FOR PUBLICATION FEBRUARY 21, 1950)

\begin{abstract}
At a conference on coal-workers' pneumoconiosis called in Cardiff in January 1947 by the Minister of Fuel and Power, it was suggested that it might be possible to re-employ men certified as cases of coal-worker's pneumoconiosis in the briquetting industry, in which the Minister anticipated an expansion. The Industrial Pulmonary Disease Committee of the Medical Research Council subsequently discussed the matter. As it is not possible to re-employ men suffering from pneumoconiosis in a very dusty environment, the Committee deemed it necessary, before giving an opinion, to assess the existing dust conditions. The Pneumoconiosis Research Unit was, therefore, asked to make a short investigation.
\end{abstract}

\section{The Briquetting Industry}

For many years small coal $\left(0-\frac{1}{8}\right.$ in.) has been compounded with pitch and pressed into coherent blocks or ovoids and used as fuel. This process has been conducted only on a relatively small scale in this country compared with Germany and France. The output here is now considerably less than it was 20 and 30 years ago, as Table I shows.

TABLE I

CoAl Utilized for BriQuetting (Million Tons)

\begin{tabular}{c|c|c}
\hline Year & Gt. Britain & France \\
\hline 1913 & 2.249 & 3.673 \\
1929 & 1.395 & 6.670 \\
1937 & 0.827 & 7.957 \\
1943 & 0.700 & - \\
1945 & 0.391 \\
1948 & $0.601\}$ Blocks & - \\
\hline
\end{tabular}

The expansion of the industry as a whole since 1947 forecast by the Minister of Fuel and Power has not, in fact, materialized to any extent. There has been some expansion of the block industry, but a decrease in the manufacture of ovoids. The home consumption of briquettes has declined because of the improved supply of raw coal, while foreign markets, which took nearly all the production before 1939, are not buying on the same scale, as costs are too high compared with that for foreign raw coal. The export situation has improved a little recently, however.

In south Wales, early in 1948, there were eight briquetting works in operation. These produced about $80 \%$ of the total output from Great Britain, and employed some 800 men.

Briquetting works have been operating in south Wales since 1870 . The product for many years was a near-cubical block, weighing from 10 to $25 \mathrm{lb}$., depending on the factory. During the 1939-45 war, the Ministry of Fuel and Power erected a number of modern plants to produce ovoids weighing about $3 \mathrm{oz}$. each.

The Briquetting Process.-Small coal and coal-tar pitch $(8 \%)$ are fed to a disintegrator, where the coal and pitch are ground and mixed. In the Ministry of Fuel and Power ovoid plants, wet duff is generally used in its undried state: no grinding is necessary. For the block plants the washed coals are dried before being ground.

The mixture of coal and pitch is elevated and discharged into the top of a pug mill or kneader. Steam jets are provided around the lower periphery of the "pugs". The steam (superheated) melts the pitch, which then coats the coal particles as they travel down the pug, the process being continuous. The warm soggy mixture coming out of the base of the pug passes into a tempering device to get rid of excess moisture. After cooling, it is passed to the press-pan and to the press-table moulds. Briquettes are pressed in a continuous stream. The finished product is usually stacked on trolleys to cool in the open, but ovoids are sometimes conveyed directly to railway wagons.

The coal and pitch are received separately in railway wagons. There are usually several large bunkers, each for holding a different type of coal, so that a satisfactory blend can be drawn off. The coal-wagons are upended and the coal passed to the appropriate bunker. Pitch is broken down somewhat before it is shovelled by hand 
from the railway wagons to hand-barrows, from which it is either tipped into hoppers or shovelled into a pre-disintegrator. In general, the coal and pitch are not touched by hand or shovel after they are transferred to the bunkers.

Both coal and pitch dust, occurring either separately or as coal particles coated with pitch, may be expected to be released into the air of briquetting works. There are often dense clouds of visible steam near the pug mills and presses. The industry may be classified as a dirty one, but not now as a dusty one. Much material is falling all the time from overhead machinery and conveyors, and the floors become quickly covered with a deposit of mixed coal and pitch aggregates. These aggregates are much too large to enter the respiratory system. They do settle on clothes, head, face, and hands, however, and, together with pitch vapour, cause skin irritation. Pitch warts were common in the past, but since 1944 regulations have been in force to control this hazard, in particular by the use of a barrier cream for face and hands and by the provision of improved washing and bathing facilities.

Coal used to be received in a dry state, and it is said that very high concentrations of dust were then common throughout the factories and in the yards down wind. Now that the coal received by the south Wales briquetting factories is invariably high in moisture content, the situation is very different. In spite of apparently very high dust concentrations in the past, no case of pneumoconiosis is known to have occurred in the briquetting industry. At one works men certified as cases of coal-worker's pneumoconiosis are working without difficulty on outside duties, mainly in connexion with the shifting of raw materials. In fact, relatively few men work in the factories actually supervising the machinery. About an equal number are, however, engaged on what is probably the dustiest operation of all, tipping and shovelling pitch from hand barrows into hoppers. This carting and shovelling of pitch requires the greatest physical effort of all the processes and would be unsuitable for many cases of pneumoconiosis for this reason alone.

\section{Sampling Dust Conditions}

Samples of air-borne dust were taken with a thermal precipitator in two representative factories, one making large blocks (Factory 1 ) and the other ovoids (Factory II). The first series of samples was spoiled by large aggregates falling into the instrument. They lodged on the hot wire of the precipitator, where they became partly volatilized, with the result that the dust deposits on the cover- glasses were greatly confused by pitch vapour condensing there. A flat plate was then erected about two inches above the entrance to the precipitator, to prevent large particles falling in ; more satisfactory samples were then obtained. Even with this protection, however, some samples had to be rejected for the same reason.

Nearly all samples contained many very small particles of "smoke" and less than $0.5 \mu$ diameter. They were probably produced by the open baskettype fires, burning briquettes for heating purposes. The microscopic appearance of these particles tended to confirm this suggested origin. Consequently, microscope counts were only made of those particles larger than $0.5 \mu$ mean diameter. It is at present generally accepted that the dust hazard in a coal-mine is best represented by the number of particles between 0.5 and $5 \mu$ diameter in a cubic centimetre of air.

Only very few samples were obtained, but most were taken at what appeared, from preliminary sampling with the P.R.U. hand-pump, to be the dustiest positions in the factories visited. The survey was only intended to be a brief one, in order to provide some rough indications of the dust levels encountered. Pitch and coal particles usually appeared on all records, though, as expected, more coal than pitch was present near the coal bunker and the reverse near the pitch hopper. No attempt has been made to count differentially the two components of the dusts. The results are given in Table II.

The maximum concentration was 130 particles/cc. $(0.5-5 \mu)$, at the mouth of the coal bunker in Factory I. This is well below that usually found in coal mines. It may be noted that the present official level of "approved" dust conditions is 650 particles/cc. $(1-5 \mu)$ for anthracite mines and $850 / \mathrm{cc}$. for other coal mines. Consequently, it can be concluded that the dust hazard in briquetting works in south Wales is, under present conditions, very small. Pitch vapour is present in the air, and its irritating properties are immediately mildly apparent to visitors.

\section{Summary and Conclusions}

A brief dust survey has been made in two briquetting factories in south Wales.

Preliminary investigations suggested that the handling of coal and pitch inside the factories, before the mixing and heating stages of the process, were the dustiest occupations, under present-day conditions, when damp or wet coal is received.

Thermal precipitator samples revealed a maximum indoor concentration of 130 particles/cc., in the size range $0.5-5 \mu$, with most concentrations less 
TABLE II

ANAlysis of Dust SAMPles From Briquette Factories

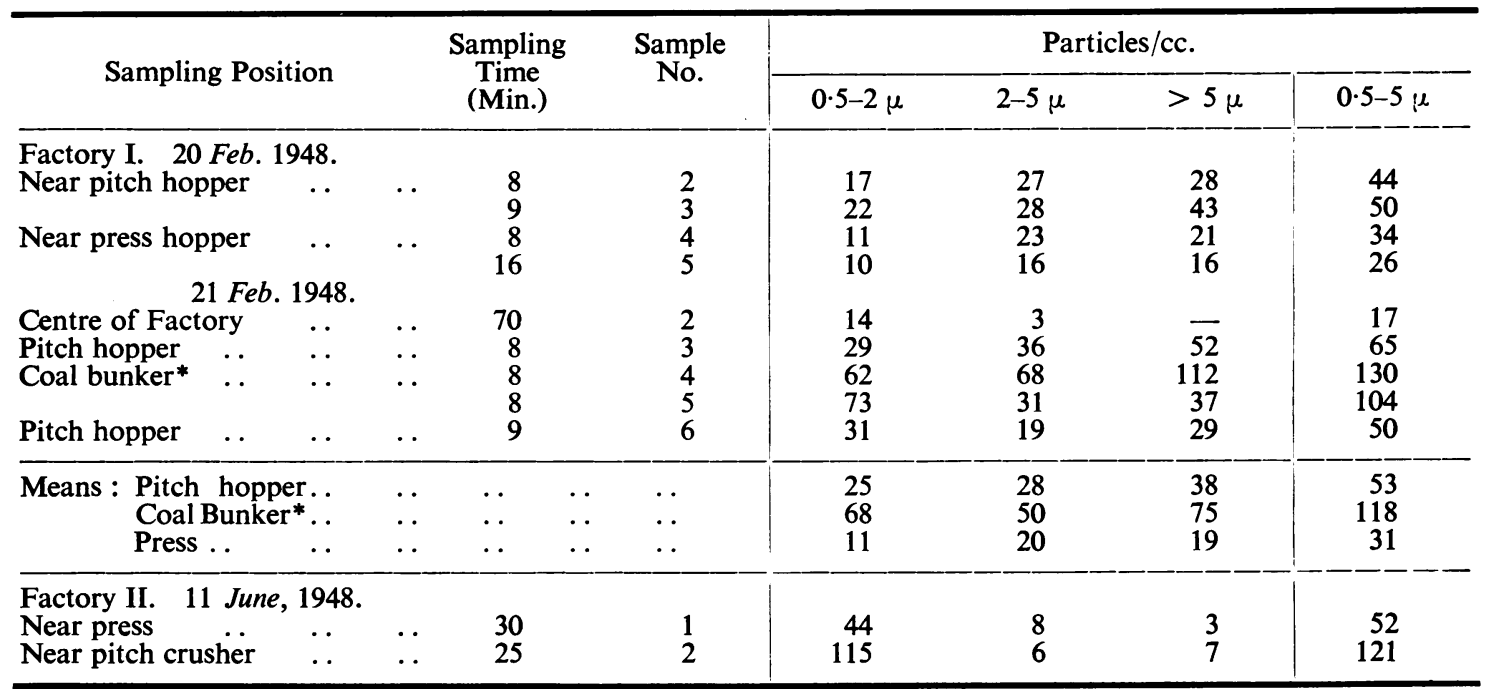

- Sampling position at mouth of bunker where coa! is raised in small buckets on an endless belt.

than 100 particles/cc. Concentrations near outdoor operations would be expected to be smaller.

After discussion with Dr. C. M. Fletcher, Director of the Pneumoconiosis Research Unit, the following conclusions were felt to be justified.

Dust concentrations in the briquetting works investigated were so low that they should constitute no risk to men with pneumoconiosis.

We know nothing of the effects of pitch vapour on the lungs of pneumoconiosis cases, but many of the more disabled men suffer from asthma-like attacks which may be precipitated by irritating fumes, so that such men might be adversely affected. It is, however, unwise to categorize any job as unsuitable for men with pneumoconiosis in general because a few may be upset by it.
The outdoor occupations in the industry are of the labouring type which are generally unsuitable for disabled men with pneumoconiosis.

There is no labour shortage in the briquetting industry in south Wales, and it is not likely in any case to be able to make any important contribution to the problem of unemployment among men certified as cases of pneumoconiosis in south Wales.

Mr. S. A. Gadd, S.W. Divisional Briquetting Officer, kindly agreed to this investigation and supplied much useful advice and information. Mr. P. V. Lloyd, S.W. Divisional Briquetting Scientist, gave valuable assistance at the factories visited and was present while the samples were being taken. 